\title{
Water-Jet Erosion of Grade-A Ship Steel: Experimental Research
}

\author{
Yupeng Cao $\mathbb{D}^{1},{ }^{1}$ Yue Zhang $\mathbb{D},{ }^{1}$ Weidong Shi $\mathbb{D},{ }^{1}$ Hua Lu $\mathbb{D}^{2},{ }^{2}$ Linwei Tan $\mathbb{D}^{1}$, \\ and Yongfei Yang ${ }^{1}$ \\ ${ }^{1}$ School of Mechanical Engineering, Nantong University, Nantong 226019, China \\ ${ }^{2}$ Nantong COSCO Shipping Engineering Co., Ltd., Nantong 226001, China \\ Correspondence should be addressed to Weidong Shi; wdshi@ntu.edu.cn and Yongfei Yang; yyf2020@ntu.edu.cn
}

Received 4 December 2020; Revised 1 January 2021; Accepted 26 February 2021; Published 10 March 2021

Academic Editor: Furen Ming

Copyright (c) 2021 Yupeng Cao et al. This is an open access article distributed under the Creative Commons Attribution License, which permits unrestricted use, distribution, and reproduction in any medium, provided the original work is properly cited.

A water-jet erosion test was carried out on grade-A ship steel to study the interaction and erosion mechanism of the water jet on the steel surface. When the water jet impacted, a STSS-1 stress-detection module was used to collect the dynamic strain signal on the rear of the ship's plate, and a scanning electron microscope, transmission electron microscope, $\mathrm{X}$-ray diffractometer, and other equipment were used to analyze the microstructure and phase of the grade-A ship steel before impact. The surface morphology of the material after impact was studied and analyzed. The impact stress of the water jet on the grade-A steel was an alternating stress, and the jet pressure decayed in the radial direction. The material surface was fatigued under the action of the jet alternating stress. After the water-jet erosion, the central area of the grade-A steel was dominated by an elongated cementite hard phase, and the peripheral area had a pearlite structure. A model for the jet erosion and peeling of grade-A ship steel was established to clarify the mechanism of erosion by the water jet.

\section{Introduction}

As a new surface-treatment technology, high-pressure water-jet technology achieves material cutting and surface cleaning and polishing through the ultra-high impact kinetic energy of the water jet [1-3]. Because of its high efficiency, wide applicability, and environmental protection, water-jet technology has been used extensively in various fields [4-7], such as pumping, rock breaking, mining, ship cleaning and rust removal, and material cutting [8-11]. Significant progress has been made in the simulation of flow field [11-17]. Guha [18] et al. proved that the attenuation of stagnation pressure along the axial direction was linear through simulation and experiment. The optimal target distance during cleaning was $5 \mathrm{D}$, and the jet had a diameter greater than $26 \mathrm{D}$ in the axial direction and $1.68 \mathrm{D}$ from the centerline. Positions beyond this reach could not be cleaned. Veerappan [19] and other researchers found that the cutting angle and removal rate of the surface roughness change with the jet parameters after nickel-based superalloy abrasive water-jet processing. Grade-A ship steel is an important steel plate for ships. Ship plates account for one-fifth of the cost of shipbuilding. Insufficient pressure during water-jet cleaning and rust removal of ship plates increases the impact time to achieve better cleaning results. However, long-term jet impact causes erosion damage to the surface of the ship plate base, which results in a decrease in mechanical properties of the steel plate surface, and affects the service life of the ship. Many research studies on water jets have focused on jetrelated parameters, material processing technology [20-26], and highly brittle materials, such as rocks and minerals [27-29]. Few reports exist on the interaction and erosion mechanism of water jets with grade-A ship steel.

A pure water jet was used to impact grade-A ship steel samples, and a strain detection module was used to detect the dynamic strain when the jet impacted the sample, using a transmission electron microscope (TEM), an X-ray diffractometer (XRD), and a scanning electron microscope (SEM). An energy spectrometer (EDS) was used to study and analyze the microstructure and phase of the material before the impact of the grade-A ship steel jet and the surface morphology of the material after the impact of the water jet. According to the dynamic strain of the material when the jet impacted the material, combined with an observation and 
analysis of the microstructure and morphology, the interaction between the water jet and the grade-A ship steel and the erosion mechanism were studied, and a grade-A ship steel jet erosion and peeling model was established.

\section{Experimental Program Design}

2.1. Sample Preparation and Experimental Equipment. The sample material was grade-A ship steel, which has a good corrosion resistance and fatigue resistance. The main components are shown in Table 1 . Five sets of samples of $50 \mathrm{~mm} \times 50 \mathrm{~mm} \times 10 \mathrm{~mm}$ were polished sequentially with 240-1200\# sandpaper. The water-jet erosion test used a water-jet test platform of the Research Center of Fluid Machinery Engineering and Technology (Jiangsu University, China). The test platform structure is shown in Figure 1. The jet medium was clean water, and the tests were carried out at room temperature. The specific experimental parameters are as follows: the water-jet pressure was $20 \mathrm{MPa}$, and the nozzle structure used is shown in Figure 2. The throat diameter was $1 \mathrm{~mm}$, the throat length was $4 \mathrm{~mm}$, and the expansion angle was $60^{\circ}$. Table 2 provides the impact time used. The STSS- 1 stress-detection module (Jinan Sigma Technology Co., Ltd, China.) was used to collect the dynamic strain signal on the back of the sample during the impact of the water jet on grade-A steel, and BSF-3AA-T resistance strain gauges were pasted on the back of the samples at three different positions. Their distribution is shown in Figure 3. The specific parameters of the strain gauge are as follows: resistance value is $120 \pm 0.5 \Omega$, sensitivity coefficient is $2.00-2.20$, and applicable temperature range is $30-80^{\circ} \mathrm{C}$. Strain gauge 2 was placed on the back of the jet impact center point, and strain gauges 1 and 3 were placed in a straight line with strain gauge 2 . The maximum output frequency of the dynamic signal measurement strain of the detection module was $1200 \mathrm{~Hz}$, the strain resolution was $0.5 \times 10^{-6}$, the range was $30000 \times 10^{-6}$, and the strain measurement error was less than $0.01 \%$.

2.2. Microstructure and Surface Topography Inspection. A metallurgical microscope (Leica DM2700_M), a transmission electron microscope (FEI TECNAI G2 F20), and an $\mathrm{X}$-ray diffractometer (Rigaku Ultima IV) were used to detect and analyze the microstructure and phase of the grade- $A$ ship steel. A scanning electron microscope (FEI Quanta $650 \mathrm{~F}$ ) with an energy spectrometer was used to visualize the microscopic morphology and determine the chemical composition of the material surface after erosion. The test results before and after the erosion were compared and analyzed, and the interaction between the water jet and surface of the grade-A ship steel and the jet erosion mechanism were studied.

\section{Discussion of Experimental Results}

3.1. Phase and Microstructure Analysis of Grade-A Ship Steel. The X-ray diffractometer was used to detect grade-A ship steel, obtaining the XRD pattern. The Jade software was applied to perform the main phase search with elements
TABLE 1: Chemical composition of grade-A ship steel.

\begin{tabular}{lllll}
\hline \multicolumn{5}{c}{ Chemical composition } \\
$\mathrm{C}$ & $\mathrm{Mn}$ & $\mathrm{Si}$ & $\mathrm{Cu}$ & $\mathrm{Mo}$ \\
\hline 0.17 & 0.64 & 0.21 & 0.02 & 0.004 \\
\hline
\end{tabular}

unrestricted, the minor phase with restricted elements, and the single peak, successively, on the XRD pattern. With search-matching of the XRD pattern, the XRD phase analysis results of grade-A ship steel were obtained, as shown in Figure 3. Figure 3 shows that the phase that corresponds to the main diffraction peak of the ship steel plate surface was ferrite. The content of ferrite was high in the grade-A steel, and its diffraction peak was strong. A cementite structure was also present in the grade-A steel. The position, shape, and size of the steel had a significant impact on the steel performance.

Figure 4(a) shows the surface metallographic structure of grade-A ship steel. Figure 4(a) and the XRD phase analysis results show that the surface of the grade-A ship steel is composed mainly of ferrite, cementite, and their superimposed structure. During the casting of grade-A steel, liquid iron was cooled initially and crystallized to form a high-temperature austenite structure. As the temperature decreased, high-temperature austenite began to transform to ferrite because the solubility of carbon in ferrite was less than austenite. The excess carbon and iron formed cementite at the grain boundaries of the original austenite. The carbon content in the cementite was high. With the formation and growth of the cementite, the carbon content around the cementite decreased, which promoted the formation of a ferrite phase. Ferrite formation promoted the formation of high-carbon areas nearby and promoted cementite growth. A superimposed structure of ferrite and cementite was formed alternately [30, 31]. Figure 4(b) shows the TEM morphology of the surface of grade-A ship steel. An observation of the morphological image, as can be seen, shows that the superimposed structure is a pearlite structure formed by alternately overlapping bright white ferrite phases and black cementite phases. The width of the strip cementite is about $0.1 \mu \mathrm{m}$.

3.2. Dynamic Strain Curve. Figure 5 shows the strain curve of the water jet that impacts the back of the grade-A ship steel sample. Figure 5(a) shows that the dynamic strain curve that was collected by the three-position strain gauge had a similar changing law. Two seconds after the water jet impacted the sample, the dynamic strain value that was induced by the jet impact tended to be stable, and the strain value was $100-125 \mu \mathrm{m}$. Strain gauge 2 pasted on the back of the jet impact center point had the largest strain value, and the values recorded by strain gauges 1 and 3 on both sides were close to each other. It can be inferred that the water-jet impact pressure attenuated in the radial direction. The dynamic strain curve that was collected by strain gauge 2 after the jet was stabilized and is used as an example for analysis as shown in Figure 5(b). Figure 5(b) shows that the dynamic strain on the back of the sample was between 110 


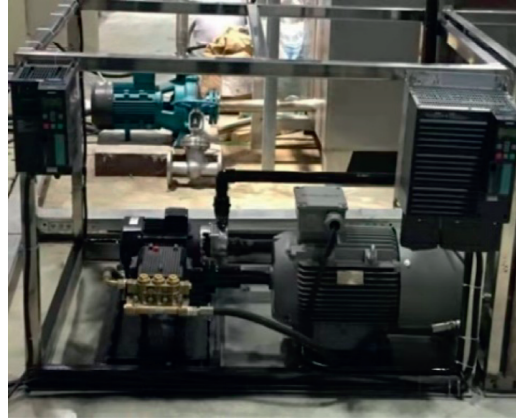

(a)

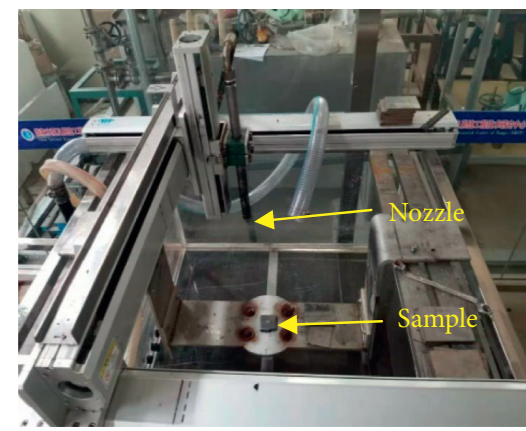

(b)

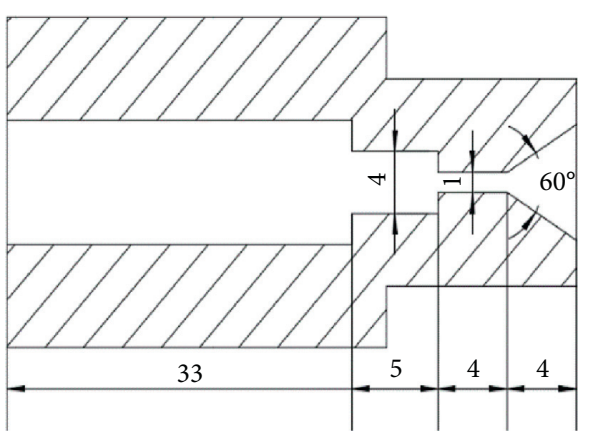

(c)

Figure 1: Water-jet experiment platform. (a) High-pressure pump. (b) Sample fixing device. (c) Nozzle structure.

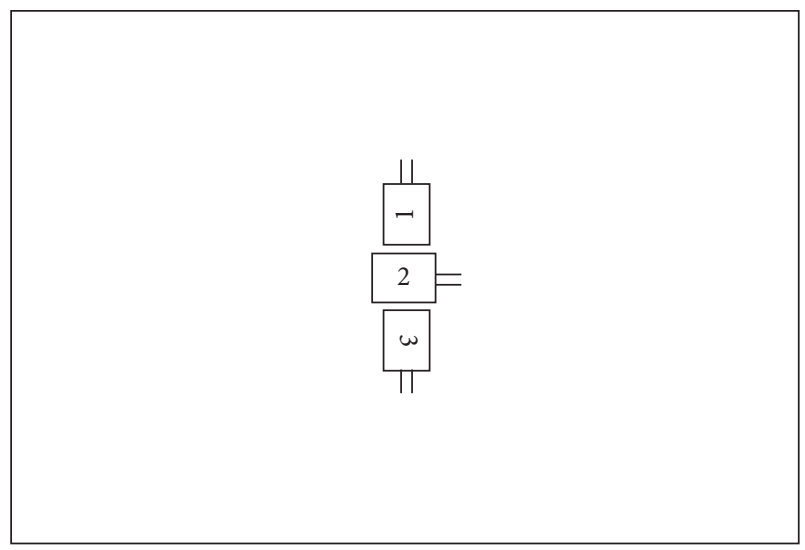

FIGURE 2: Schematic diagram of strain-gauge location.

TABLE 2: Impact time of different samples.

\begin{tabular}{lccccc}
\hline Numbering & 1 & 2 & 3 & 4 & 5 \\
\hline Time/min & 0.5 & 1 & 2 & 5 & 10 \\
\hline
\end{tabular}

and $125 \mu \mathrm{m}$, the average strain was $115 \mu \mathrm{m}$, and the strain amplitude was between 3 and $5 \mu \mathrm{m}$. Combined with the related theory of impact dynamics, according to the dynamic strain of the water jet impacting the back of the grade-A steel sample, it can be inferred that the force on the sample surface was an alternating stress.

\subsection{Analysis of Surface Morphology and Composition after Jet Erosion by Grade-A Ship Steel}

3.3.1. Surface Topography Analysis. An optical microscope was used to observe samples that were eroded by the water jet at different times. The observation results are as follows. No damage was visible on the surface of sample 1 after $0.5 \mathrm{~min}$ of impact. Erosion damage appeared in the center of the impact area of sample 2 after 1 min of impact. Round damage areas appeared on sample 3 after impact for 2 min, and sample 4 was damaged after $5 \mathrm{~min}$ of impact. The area was obviously enlarged, and the damage area formed by the erosion of sample 5 after 10 min of impact was not significantly larger than that of sample 4 , and the surface was destroyed completely. A scanning electron microscope was used to study sample 5. Figure 6 shows the SEM topography images of sample 5 at different positions on the surface of sample 5 after water jet erosion. Figure 6(a) shows that the erosion and wear of the center of the water jet impact area were more obvious than those in the peripheral area. The center erosion and wear area was a circular area with a diameter of $\sim 300 \mu \mathrm{m}$, and the peripheral area was a ring with a distance of $\sim 150-800 \mu \mathrm{m}$ from the center point. The area which was represented by bright white balls of different sizes appeared in the peripheral area. Figure 6(b) shows the SEM topography of the central erosion area, and Figures 6(c) and 6(d) are the SEM topography of the peripheral area. Figure 6(b) shows long strips of tissue and spherical particles in the central area of the jet erosion. The grain boundary of the material surface had a low resistance to damage and was first damaged by erosion [32]. Figures 6(c) and 6(d) show that under the action of the alternating stress of the water jet, the surface of the grade-A steel was eroded. Fatigue microcracks occurred at the grain boundaries. The spherical objects and other hard-phase structures near the grain boundaries were destroyed, and spherical objects with clear boundaries were visible.

3.3.2. EDS Component Analysis. To avoid introducing background information into the sampling process of microphase and to ensure that the data obtained by EDS are not affected by the random error of the instrument, the content of element under the same phase across different positions was collected by using an energy spectrometer. Then, by comparing and analyzing the detection results, the background information that may be introduced during sampling is removed. EDS analysis was performed on the spherical objects in the outer area that were eroded by the water jet as shown in Figure 6(d) and the long bars in the central area as shown in Figure 6(b). The corresponding EDS spectrum is shown in Figure 7. Figure 7(a) shows the energy spectrum analysis result of the spherical object in the peripheral area after water-jet erosion. The EDS result shows that it contains mainly elemental $\mathrm{Fe}, \mathrm{C}, \mathrm{O}, \mathrm{Mn}$, and $\mathrm{Si}$. The atomic fractions of $\mathrm{Fe}, \mathrm{C}$, and $\mathrm{O}$ were $82.8 \%, 14.4 \%$, and $1.9 \%$, respectively. By combining the metallographic and microstructure of the grade-A ship steel in Figure 4, according to the EDS results and calculated from the atomic 


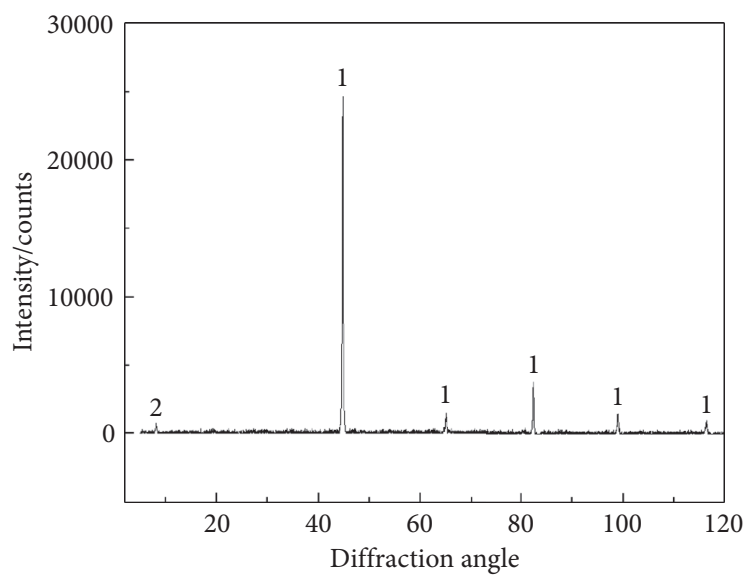

1.a-Fe

2. $\mathrm{Fe}_{3} \mathrm{C}$

FIGURE 3: XRD pattern of grade-A ship steel.

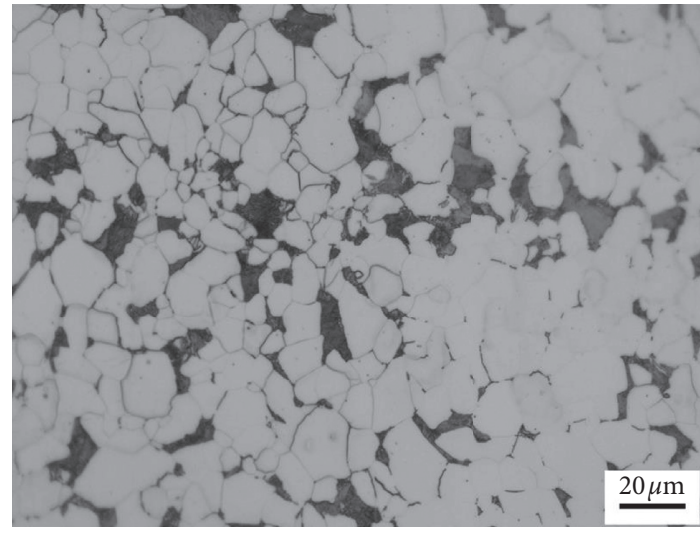

(a)

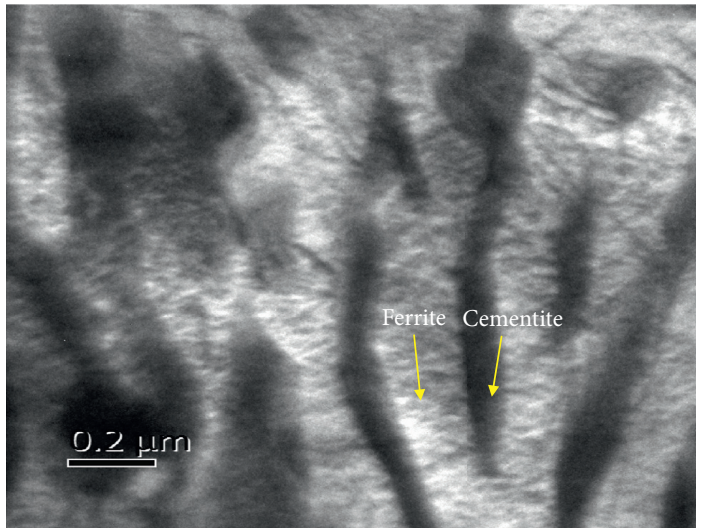

(b)

FIgURE 4: Metallographic and microstructure morphology of grade-A ship steel. (a) Optical metallography. (b) TEM image.

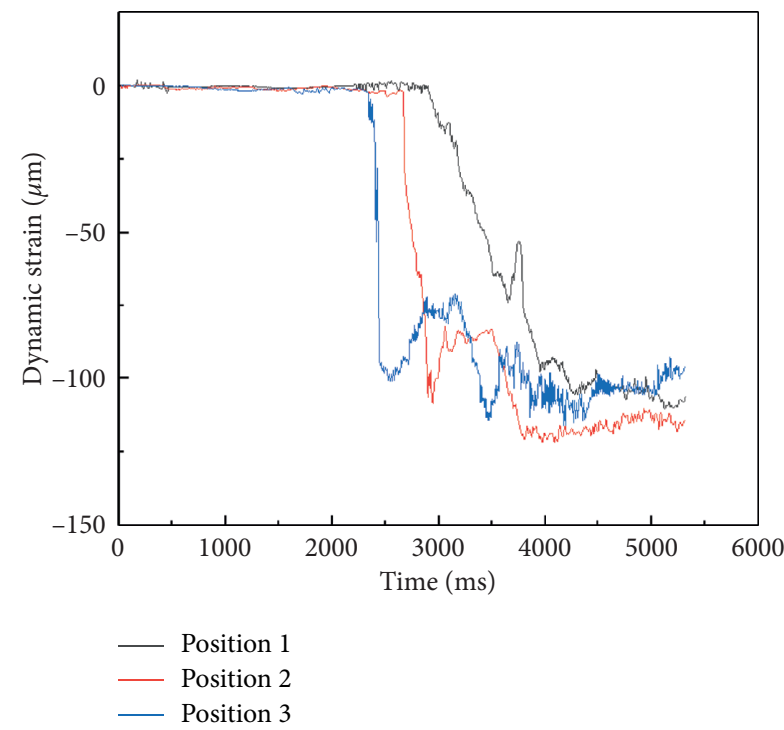

(a)

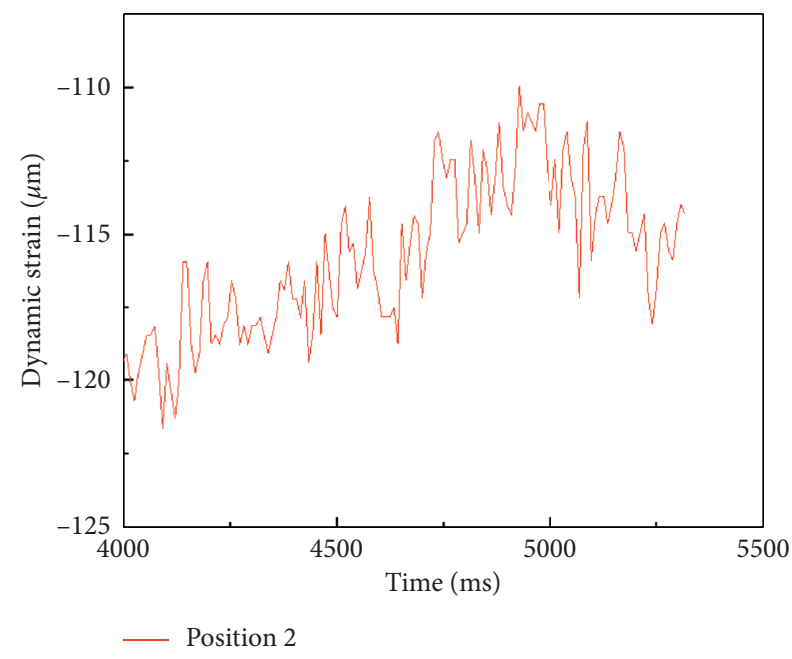

(b)

Figure 5: Dynamic strain curve on the back of the grade-A ship steel sample. (a) Dynamic strain obtained by three detection points. (b) Partial enlarged view of strain gauge 2 that recorded the dynamic strain. 


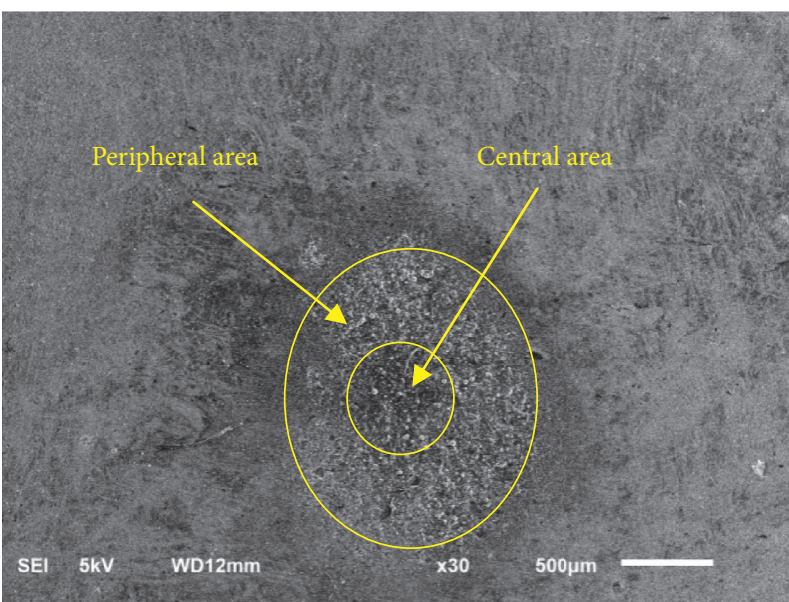

(a)

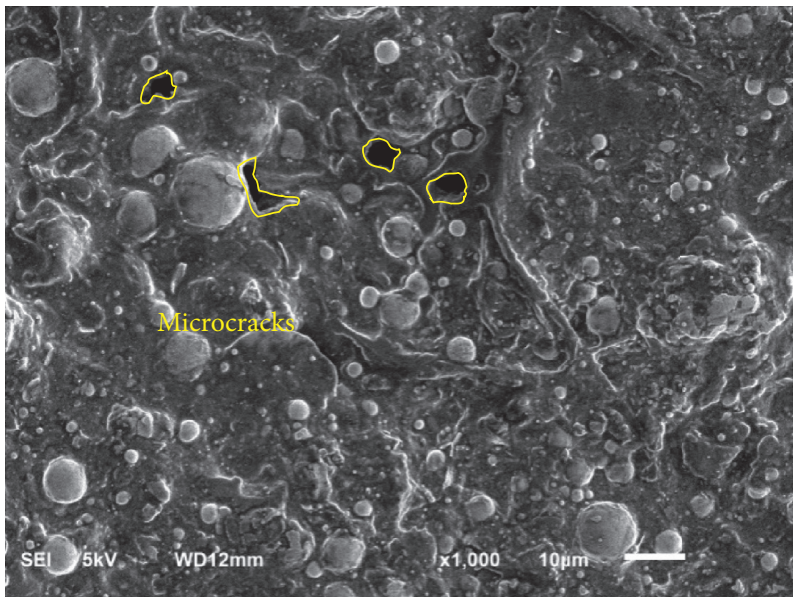

(c)

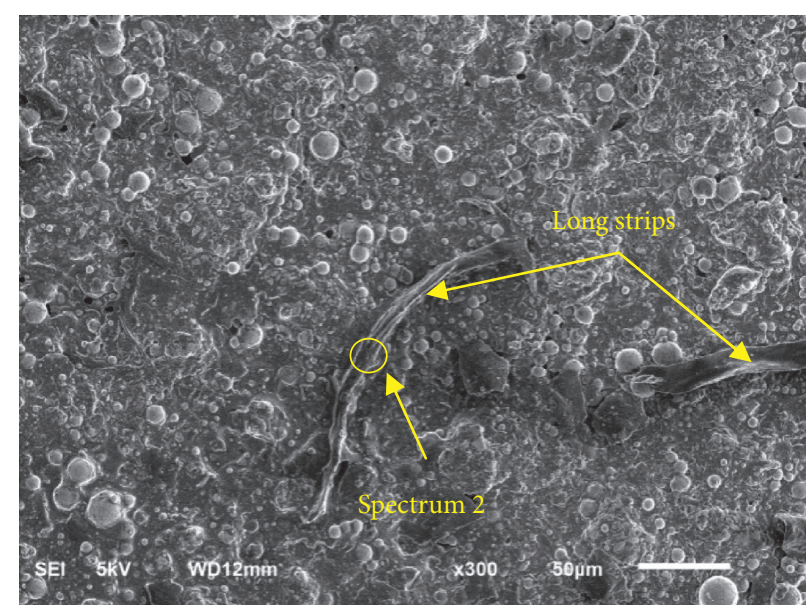

(b)

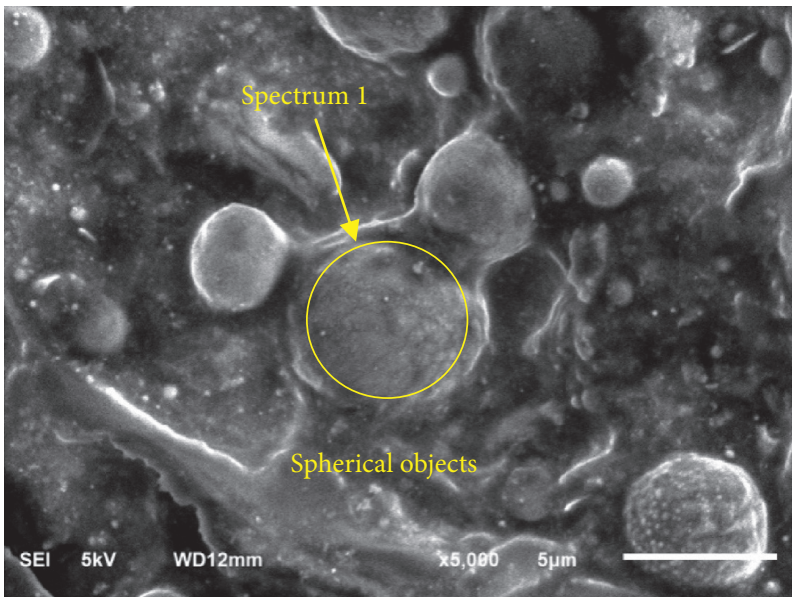

(d)

FIGURE 6: Surface SEM images of different areas of material after erosion. (a) Erosion of the entire area. (b) Long strips in the central area. (c) Erosion of microcracks. (d) Spherical objects in the peripheral area.

ratio, in combination with the XRD phase analysis results, it can be seen that the spherical objects are mostly pearlite that was formed by stacking ferrite and cementite $\left(\mathrm{Fe}_{3} \mathrm{C}\right)$. Figure 7(b) shows the energy spectrum analysis result of the long strip in the center area of the jet after the water jet was eroded. The EDS result shows that it contains mainly Fe, C, $\mathrm{O}, \mathrm{Si}, \mathrm{Mn}$, and $\mathrm{Mo}$. The atomic fractions of $\mathrm{Fe}, \mathrm{C}$, and $\mathrm{O}$ were $71.9 \%, 22.0 \%$, and $4.8 \%$, respectively. The iron content decreased, the carbon and oxygen content increased, and the iron-carbon atomic ratio was close to $3: 1$. In combination with the XRD phase analysis results, the atomic ratio shows that this long strip was mainly cementite $\left(\mathrm{Fe}_{3} \mathrm{C}\right)$; its oxygen content is more than double, the content of other metal elements also increased, and various metal oxides precipitated around the cementite.

3.4. Grade-A Ship Steel Jet Erosion and Stripping Model. The previous dynamic strain analysis shows that the impact force of the water jet was an alternating stress, and the gradeA ship steel specimens exhibited fatigue failure because of the alternating stress. According to previous SEM surface morphology and EDS analysis, the jet induced alternating stress to cause fatigue failure. Different microstructures existed on the surface of the grade-A ship steel samples. Figure 8 provides a schematic diagram of the "Grade-A ship steel water-jet erosion and peeling model." The surface of the grade-A ship steel sample that was loaded by water-jet impact is shown in Figure 8(a). The alternating stress that was generated by the jet impact fatigued the sample surface and produced microcracks at the grain boundaries, as shown in Figure 8(b). Under the continuous impact of the water jet and the action of the water wedge, the surface microcracks of the material continued to expand and develop. Because of the low hardness of the ferrite on the grade-A ship steel surface, the surface was the first to suffer fatigue damage, and damage holes of different diameters appeared in the jet erosion area phenomenon, as shown in Figure 8(c). As the impact time of the water jet increased, the pressure in the center area of the jet increased, the ferrite with lower hardness was almost completely eroded during the crack expansion process, and part of the hard-phase structure with a poor bonding force to the matrix peeled off gradually and eroded. The pits are shown in Figure 8(d); the impact 


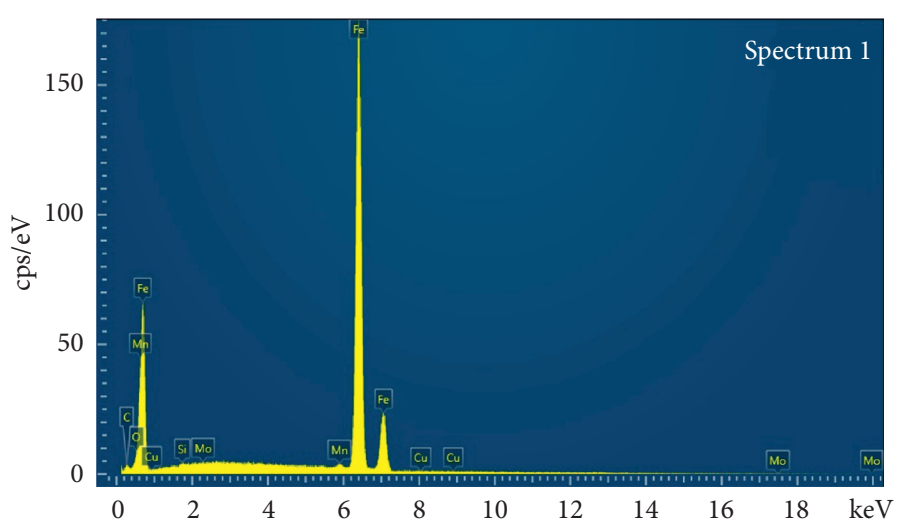

\begin{tabular}{lcc}
\hline Element & $\mathrm{Wt} \%$ & At\% \\
\hline $\mathrm{Fe}$ & 94.91 & 82.8 \\
$\mathrm{C}$ & 3.54 & 14.4 \\
$\mathrm{O}$ & 0.61 & 1.9 \\
$\mathrm{Mn}$ & 0.64 & 0.6 \\
$\mathrm{Si}$ & 0.18 & 0.3 \\
$\mathrm{Cu}$ & 0 & 0 \\
$\mathrm{Mo}$ & 0 & 0 \\
Total & & 100 \\
\hline
\end{tabular}

(a)

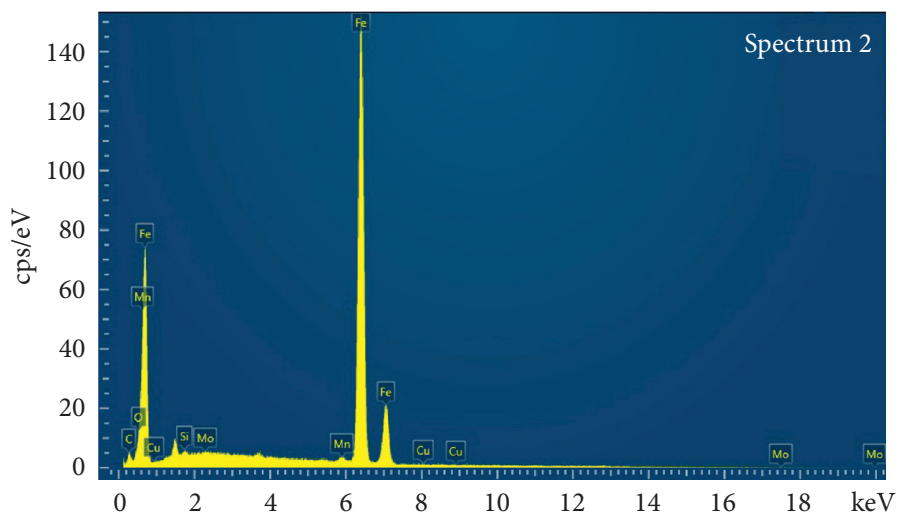

\begin{tabular}{|c|c|c|}
\hline Element & $\mathrm{Wt} \%$ & At $\%$ \\
\hline $\mathrm{Fe}$ & 90.90 & 71.9 \\
\hline C & 5.99 & 22.0 \\
\hline $\mathrm{O}$ & 1.74 & 4.8 \\
\hline $\mathrm{Mn}$ & 0.69 & 0.6 \\
\hline $\mathrm{Si}$ & 0.37 & 0.6 \\
\hline $\mathrm{Cu}$ & 0.08 & 0.1 \\
\hline Mo & 0.22 & 0.1 \\
\hline Total & & \\
\hline
\end{tabular}

(b)

FIGURE 7: EDS element analysis. (a) Spherical object. (b) Long strip.

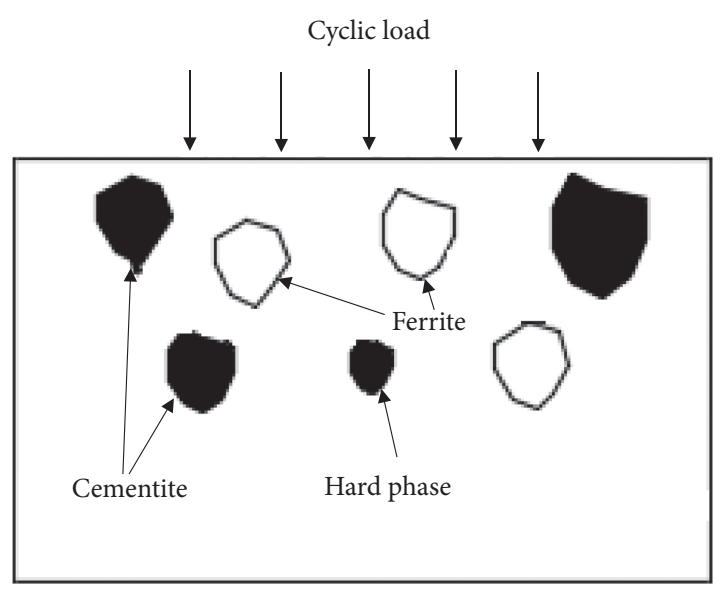

(a)

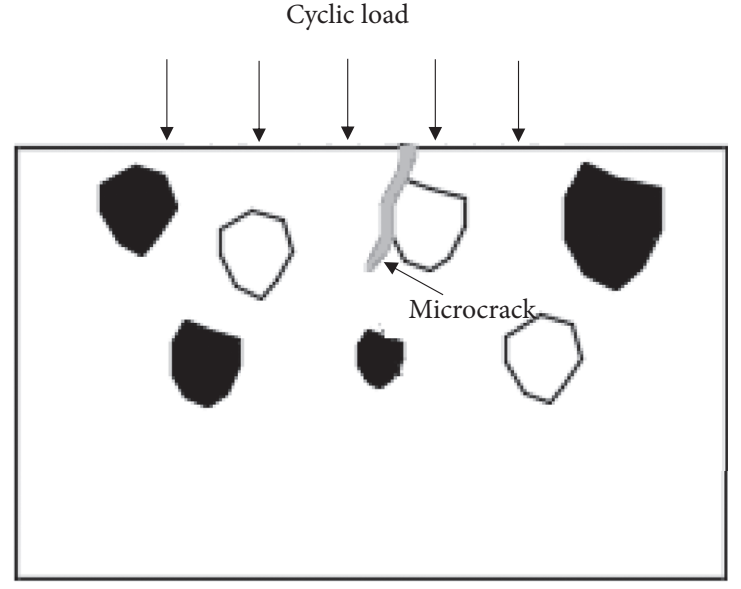

(b)

FIgure 8: Continued. 


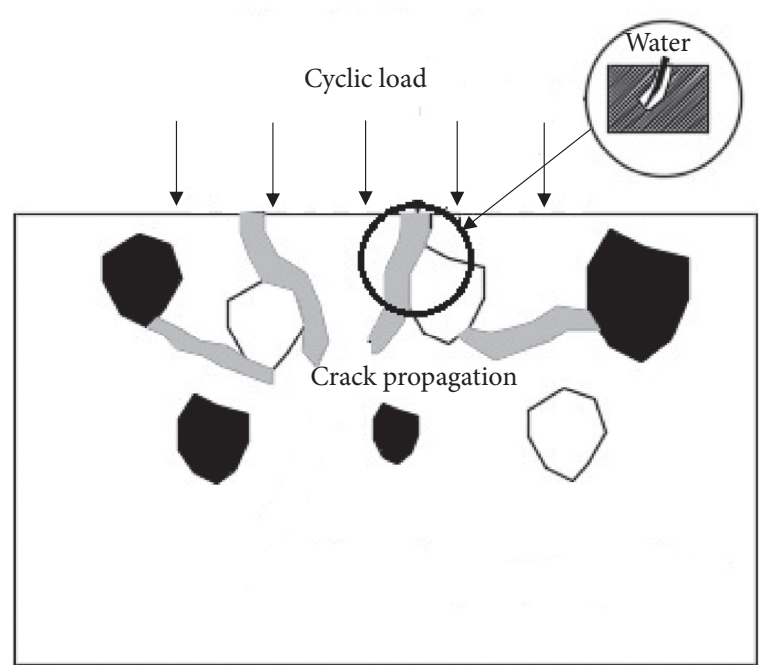

(c)

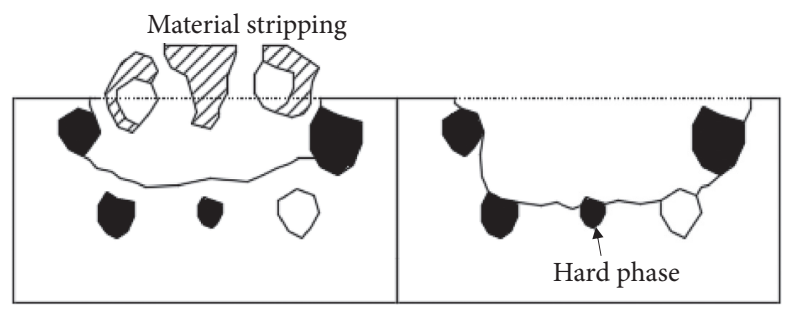

(d)

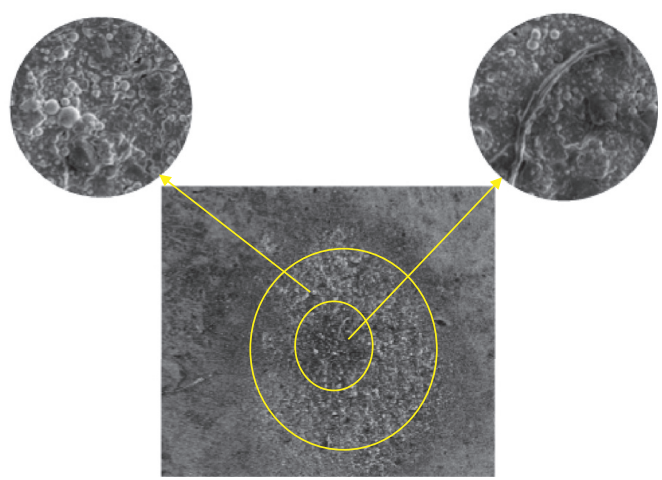

(e)

Figure 8: Grade-A ship steel jet erosion and peeling model. (a) Cyclic stress. (b) Microcrack initiation. (c) Water wedge. (d) Material stripping. (e) After erosion.

pressure of the water jet decayed in the radial direction, and the pressure in the center of the jet was largest. After the erosion, only the hard-phase structure represented by cementite remained and the jet pressure in the peripheral area was relatively high. Spherical pearlite tissue remained had not been peeled off completely. The material after jet erosion is shown in Figure 8(e).

\section{Conclusions}

(1) The impact force of the water jet attenuated in the radial direction, and the average strain on the back of the central area of the grade-A steel was $115 \mu \mathrm{m}$ at $20 \mathrm{MPa}$. The strain amplitude was $3-5 \mu \mathrm{m}$, and the dynamic strain was between 110 and $125 \mu \mathrm{m}$. The impact of the water jet on the material was an alternating stress.

(2) The grade-A ship steel matrix was composed of ferrite and pearlite. The surface of the material underwent fatigue failure under the action of the jet alternating stress. After erosion, the center area of the grade-A steel became a long strip of cementite hard phase. Uneroded pearlite tissue remained in the peripheral area, and the carbon content decreased gradually from the center to the peripheral area.
(3) A grade-A ship steel jet erosion peeling model was established, and the process of the material surface was explained from the microcracks at the grain boundary to the gradual peeling of different hardness structures under the action of the alternating stress of the water jet and the water wedge. The corrosion mechanism was clarified.

\section{Data Availability}

The data used to support the findings of this study are available from corresponding author via e-mail.

\section{Conflicts of Interest}

The authors declare that they have no conflicts of interest.

\section{Acknowledgments}

This research was funded by the National Key Research and Development Project of China (no. 2019YFB2005300), National High-Tech Ship Scientific Research Project of 
China (no. MIIT[2019]360), National Natural Science Foundation of China (nos. 51505236 and 51979138), and China Postdoctoral Science Foundation (no. 2019M651931).

\section{References}

[1] R. Hillegersberg, W. Kort, F. Kate et al., "Water-jet-cooled Nd: YAG laser coagulation: selective destruction of rat liver metastases," Lasers in Surgery and Medicine, vol. 11, no. 5, pp. 445-454, 2010.

[2] S. Tang, S. Yuan, and Y. Zhu, "Convolutional neural network in intelligent fault diagnosis toward rotatory Machinery," IEEE Access, vol. 8, pp. 86510-86519, 2020.

[3] L. Bai, L. Zhou, X. Jiang, Q. Pang, and D. Ye, "Vibration in a multistage centrifugal pump under varied conditions," Shock and Vibration, vol. 2019, Article ID 2057031, 9 pages, 2019.

[4] M. S. Alsoufi, "State-of-the-Art in abrasive water jet cutting technology and the promise for micro-and nano-machining," International Journal of Mechanical Engineering and Applications, vol. 5, no. 1, pp. 1-14, 2017.

[5] G. Peng, F. Fan, L. Zhou et al., "Optimal hydraulic design to minimize erosive wear in a centrifugal slurry pump impeller," Engineering Failure Analysis, vol. 120, Article ID 105105, 2020.

[6] V. M. Tabie, M. O. Koranteng, A. Yunus, and F. Kuuyine, "Water-jet guided laser cutting technology- an overview," Lasers in Manufacturing and Materials Processing, vol. 6, no. 2, pp. 189-203, 2019.

[7] H.-T. Liu, "Advanced waterjet technology for machining curved and layered structures," Curved and Layered Structures, vol. 6, no. 1, pp. 41-56, 2019.

[8] P. A. Hwang, Y.-K. Poon, and J. Wu, "Temperature effects on generation and entrainment of bubbles induced by a water jet," Journal of Physical Oceanography, vol. 21, no. 10, pp. 1602-1605, 1991.

[9] B. Schumacher, J.-P. Charton, T. Nordmann, M. Vieth, M. Enderle, and H. Neuhaus, "Endoscopic submucosal dissection of early gastric neoplasia with a water jet-assisted knife: a Western, single-center experience," Gastrointestinal Endoscopy, vol. 75, no. 6, pp. 1166-1174, 2012.

[10] Y. Yang, L. Zhou, W. Shi et al., "Interstage difference of pressure pulsation in a three-stage electrical submersible pump," Journal of Petroleum Science and Engineering, vol. 196, Article ID 107653, 2020.

[11] C. Wang, X. Wang, W. Shi et al., "Experimental investigation on impingement of a submerged circular water jet at varying impinging angles and Reynolds numbers," Experimental Thermal and Fluid Science, vol. 89, 2017.

[12] G. Peng, X. Huang, L. Zhou, G. Zhou, and H. Zhou, "Solidliquid two-phase flow and wear analysis in a large-scale centrifugal slurry pump," Engineering Failure Analysis, vol. 114, Article ID 104602, 2020.

[13] N. Kumar and M. Shukla, "Finite element analysis of multiparticle impact on erosion in abrasive water jet machining of titanium alloy," Journal of Computational and Applied Mathematics, vol. 236, no. 18, pp. 4600-4610, 2012.

[14] J. C. Lasheras, E. Villermaux, and E. J. Hopfinger, "Break-up and atomization of a round water jet by a high-speed annular air jet," Journal of Fluid Mechanics, vol. 357, pp. 351-379, 1998.

[15] C.-Y. Hsu, C.-C. Liang, T.-L. Teng, and A.-T. Nguyen, “A numerical study on high-speed water jet impact," Ocean Engineering, vol. 72, no. nov.1, pp. 98-106, 2013.
[16] L. Bai, L. Zhou, C. Han, Y. Zhu, and W. Shi, "Numerical study of pressure fluctuation and unsteady flow in a centrifugal pump," Processes, vol. 7, no. 6, p. 354, 2019.

[17] M. G. Mostofa, K. Y. Kil, and A. J. Hwan, "Computational fluid analysis of abrasive waterjet cutting head," Journal of Mechanical Science and Technology, vol. 24, no. 1, pp. 249252, 2010.

[18] A. Guha, R. M. Barron, and R. Balachandar, "An experimental and numerical study of water jet cleaning process," Journal of Materials Processing Technology, vol. 211, no. 4, pp. 610-618, 2011.

[19] R. M. . VeerappanG, "Experimental investigations on abrasive water jet machining of nickel-based superalloy," Journal of the Brazilian Society of Mechanical Ences and Engineering, vol. 41, no. 11, pp. 1-12, 2019.

[20] D. Begic-Hajdarevic, A. Cekic, M. Mehmedovic et al., "Experimental study on surface roughness in abrasive water jet cutting," Procedia Engineering, vol. 100, pp. 394-399, 2015.

[21] V. Tangwarodomnukun, J. Wang, C. Z. Huang, and H. T. Zhu, "Heating and material removal process in hybrid laserwaterjet ablation of silicon substrates," International Journal of Machine Tools and Manufacture, vol. 79, pp. 1-16, 2014.

[22] M. Babu and N. Muthukrishnan, "Investigation on surface roughness in abrasive water-jet machining by the response surface method," Materials and Manufacturing Processes, vol. 29, no. 11-12, pp. 1422-1428, 2014.

[23] M. Habak and J. L. Lebrun, "An experimental study of the effect of high-pressure water jet assisted turning (HPWJAT) on the surface integrity," International Journal of Machine Tools and Manufacture, vol. 51, no. 9, pp. 661-669, 2011.

[24] G. A. Escobar-Palafox, R. S. Gault, and K. Ridgway, "Characterisation of abrasive water-jet process for pocket milling in inconel 718," Procedia CIRP, vol. 1, no. 1, pp. 404-408, 2012.

[25] A. Melaibari, J. Zhao, P. Molian et al., "Ultrahard boron nitride material through a hybrid laser/waterjet based surface treatment," Acta Materialia, vol. 102, pp. 315-322, 2016.

[26] R. M. ChillmanA and M. Hashish, "Waterjet and water-air jet surface processing of a titanium alloy: a parametric evaluation," Journal of Manufacturing Science and Engineering, vol. 132, no. 1, pp. 165-174, 2016.

[27] G. Karakurt, K. Aydin, and K. Aydiner, “An experimental study on the depth of cut of granite in abrasive waterjet cutting," Materials and Manufacturing Processes, vol. 27, no. 5, pp. 538-544, 2012.

[28] C. Shen, B. Lin, and H. Wu, "High pressure water jet slotting and influence on permeability of coal seams[J]," Journal of China Coal Society, vol. 36, no. 12, pp. 2058-2063, 2011.

[29] S. Dehkhoda and M. Hood, "An experimental study of surface and sub-surface damage in pulsed water-jet breakage of rocks," International Journal of Rock Mechanics and Mining Sciences, vol. 63, pp. 138-147, 2013.

[30] X.-Y. Zhao, X.-M. Zhao, H.-B. Han, C.-Y. Dong, and Y. Yang, "Enhancement of pearlite transformation by warm rolling in 1.0C-1.5Cr steel," Materials Science and Technology, vol. 36, no. 13, pp. 1431-1439, 2020.

[31] N. Shimizu and T. Imao, "Effect of discontinuous change in cooling rate during continuous cooling on pearlitic transformation behavior of steel," vol. 17, no. 8, pp. 469-476, 2019.

[32] L. Huang, J. Folkes, P. Kinnell, and P. H. Shipway, "Mechanisms of damage initiation in a titanium alloy subjected to water droplet impact during ultra-high pressure plain waterjet erosion," Journal of Materials Processing Technology, vol. 212, no. 9, pp. 1906-1915, 2012. 